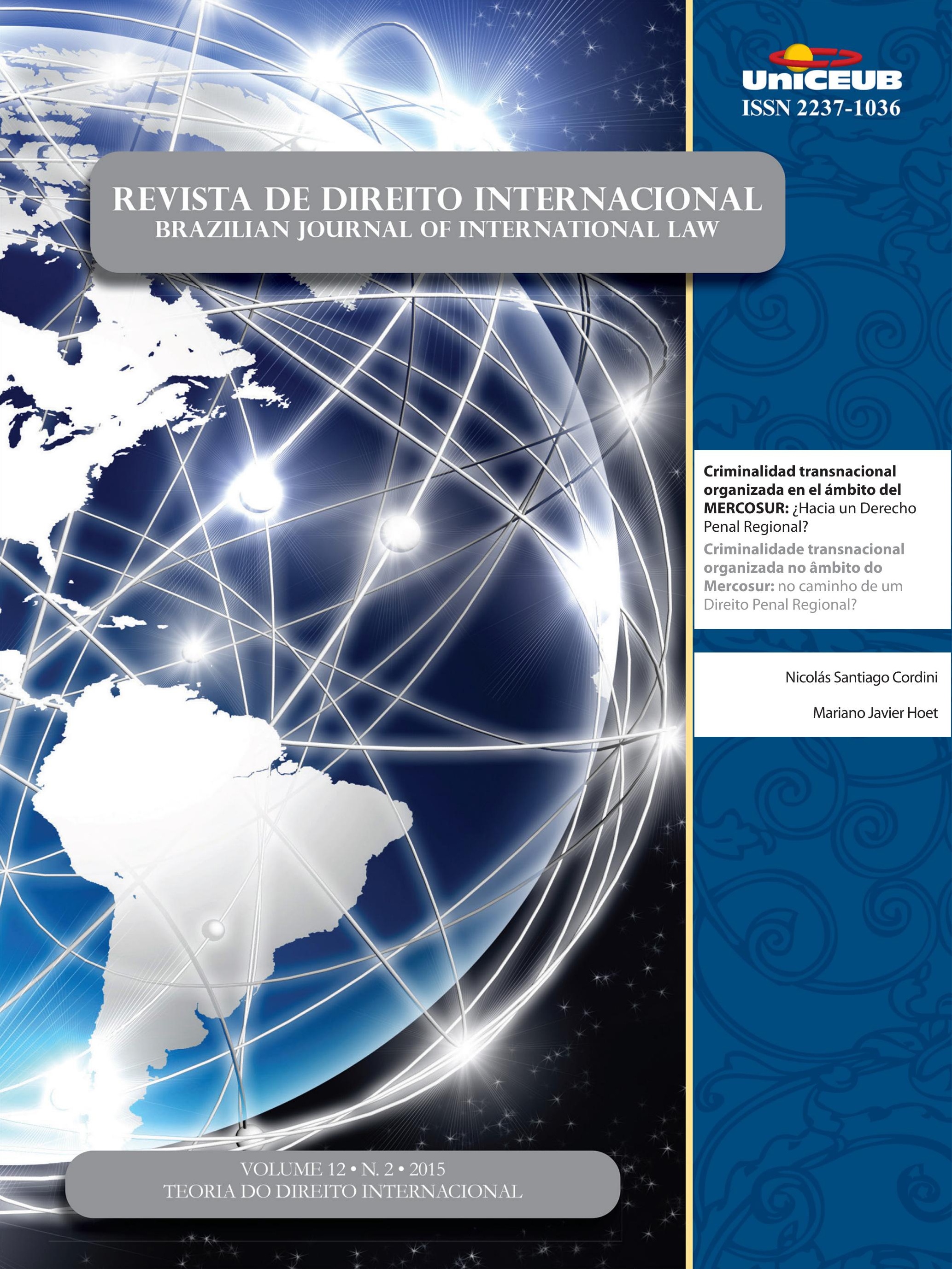




\section{Sumário}

CrôNiCAS DA ATUALIDADE do DiREITo INTERnACIONAL ..................................................... 2 Sarah Dayanna Lacerda Martins Lima, Carina Costa de Oliveira e Erika Braga

CrôniCas do Direito InternaCional dos InVESTIMENTOS ..............................................12 Nitish Monebhurrun

Por que voltar a Kelsen, o jurista do século XX ? 16 Inocêncio Mártires Coelho

O Princípio da Efetividade como conteúdo da norma fundamental (GrundNorm) DE KELSEN

Carlos Alberto Simões de Tomaz e Renata Mantovani de Lima

A JURIDIFICAÇÃo DE CONFLITOS POLÍTICOS NO DIREITO INTERNACIONAL PÚBLICO CONTEMPORÂ-

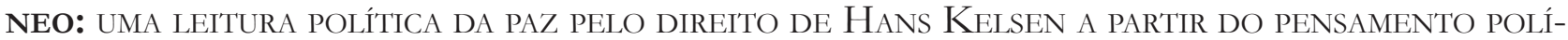
TICO De Claude Lefort

Arthur Roberto Capella Giannattasio

O SINCRETISMO TEÓRICO NA APROPRIAÇÃO DAS TEORIAS MONISTA E DUALISTA E SUA QUESTIONÁVEL UTILIDADE COMO CRITÉRIO PARA A CLASSIFICAÇÃO DO MODELO BRASILEIRO DE INCORPORA-

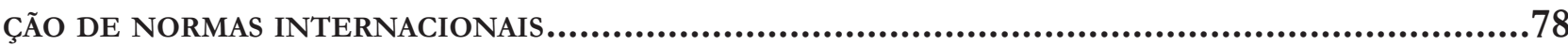
Breno Baía Magalhães

Direito Global em Pedaços: Fragmentação, Regimes e Pluralismo .98 Salem Hikmat Nasser

Por uma TeOria JURÍdica da INTEGRaÇão REgIONAL: A INTER-RELAÇÃO DiREITO INTERNO, DiREITO INTERNACIONAL PÚBLICO E DIREITO DA INTEGRAÇÃO Jamile Bergamaschine Mata Diz e Augusto Jaeger Júnior

A teOria DA INTERCONSTITUCIONALIDADE: UMA ANÁlISE COM BASE NA AMÉRICA LATINA...........160 Daniela Menengoti Ribeiro e Malu Romancini 
O DIÁLOGO HERMENÊUTICO E A PERGUNTA ADEQUADA À APLICAÇÃo DOS TRATADOS INTERNACIONAIS DE DIREITOS HUMANOS NO BRASIL: CAMINHOS PARA O PROCESSO DE INTERNACIONALIZAÇÃO

DA CONSTITUIÇÃO...................................................................................... 176

Rafael Fonseca Ferreira e Celine Barreto Anadon

O DIREITO COMPARADO NO STF: INTERNACIONALIZAÇÃO DA JURISDIÇÃO CONSTITUCIONAL BRASILEIRA

Carlos Bastide Horbach

THE PHILOSOPHY OF INTERNATIONAL LAW IN CONTEMPORARY SCHOLARSHIP: OVERCOMING NE-

GLIGENCE THROUGH THE GLOBAL EXPANSION OF HUMAN RIGHTS

Fabrício Bertini Pasquot Polido, Lucas Costa dos Anjos e Vinícius Machado Calixto

OpORTUNIDADES E DESAFIOS DAS TWAIL NO CONTEXTO LATINO-AMERICANO A PARTIR DE PERSPECTIVAS DOS POVOS INDÍGENAS AO DIREITO INTERNACIONAL

Fernanda Cristina de Oliveira Franco

Por Que uma ANÁlise ECONÔMICA Do DIREITO INTERNACIONAL PÚBLICO? DESAFIOS E PERSPECTIVAS DO MÉTODO NO BRASII

Gustavo Ferreira Ribeiro e Jose Guilherme Moreno Caiado

ANÁliSE ECONÔMICA do DIREITO INTERNACIONAL .263 Michele Alessandra Hastreiter e Luís Alexandre Carta Winter

RACIONALIDADE ECONÔMICA E OS ACORDOS BILATERAIS DE INVESTIMENTO 284 Michele Alessandra Hastreiter e Luís Alexandre Carta Winter

LOOKING FOR A BRICS PERSPECTIVE ON INTERNATIONAL LAW .304 Gabriel Webber Ziero

A INFLUÊNCIA DO DIREITO DESPORTIVO TRANSNACIONAL NO ORDENAMENTO JURÍDICO BRASILEIRO: DA REPRODUÇÃO DE NORMAS À APLICAÇÃO DIRETA PELA JURISDIÇÃO ESTATAL.......................3324 Tiago Silveira de Faria

CONVENCIONALIZAÇÃo DO DIREITO CIVIL: A APLICAÇÃo DOS TRATADOS E CONVENÇÕES INTERNACIONAIS NO ÂMBITO DAS RELAÇÕES PRIVADAS . 
NATIONAL JUdGES AND COURTS AS INSTITUTIONS FOR GLOBAL ECONOMIC GOVERNANCE 356

Juízes e tribunais nacionais como instituições para a governança global 356 Camilla Capucio

Is Trade Governance Changing? 371 Alberto do Amaral Júnior

OS FUNDOS ABUTRES: MEROS PARTICIPANTES DO CENÁRIO INTERNACIONAL OU SUJEITOS PERANTE O DIREITO INTERNACIONAL? 384

Guilherme Berger Schmitt

SHAREHOLDER AGREEMENTS IN PUBLICLY TRADED COMPANIES: A COMPARISON BETWEEN THE

U.S. AND BRAZIL. 402 Helena Masullo

REgulaÇÃo DO INVESTIMENTO ESTRANGEIRO DIRETO NO BRASIL: DA RESISTÊNCIA AOS TRATADOS BILATERAIS DE INVESTIMENTO À EMERGÊNCIA DE UM NOVO MODELO REGULATÓRIO 421 Fabio Morosini e Ely Caetano Xavier Júnior

DA QUALIFICAÇÃo JURÍDiCA dAS Distintas FORMAS DE PRESTAÇão TECNOLÓGICA: BREVE ANÁLISE DO MARCO REGULATÓRIO INTERNACIONAL

Daniel Amin Ferraz

REDEFINING TERRORISM: THE DANGER OF MISUNDERSTANDING THE MODERN WORLD'S GRAVEST THREAT

Jennifer Breedon

As EXECUÇões SELETIVAS E A RESPONSABILIZAÇÃo DE AGENTES TERRORISTAS 485 Alexandre Guerreiro

INTERNATIONAL CRIMINALS AND THEIR VIRTUAL CURRENCIES: THE NEED FOR AN INTERNATIONAL EFFORT IN REGULATING VIRTUAL CURRENCIES AND COMBATING CYBER CRIME Joy Marie Virga

Criminalidad transnacional organizada en el Ámbito del MERCOSUR: ¿Hacia un Derecho Penal Regional?. .528 Nicolás Santiago Cordini e Mariano Javier Hoet 
RUMO À INTERNACIONALIZAÇÃo DA PROTEÇÃO PENAL DO MEIO AMBIENTE: DOS ECOCRIMES AO ECOCÍDIO

Kathia Martin-Chenut, Laurent Neyret e Camila Perruso

Engaging the U.N. Guiding Principles on Business and Human Rights: the inter-AMERICAN COMMISSION ON HUMAN RIGHTS \& THE EXTRACTIVE SECTOR 571 Cindy S. Woods

O DIREITO HUMANO À COMUNICAÇÃo PRÉVIA E PORMENORIZADA DAS ACUSAÇÕES NOS PROCESSOS administrativos: O desprezo do Superior Tribunal de Justiça ao Pacto de San José da Costa Rica e À Corte Interamericana de Direitos Humanos .590

Daniel Wunder Hachem e Eloi Pethechust

A responsabilidade internacional do Brasil em FaCe do CONTRole de ConVENCionaliDADE EM SEDE DE DIREITOS HUMANOS: CONFLITO DE INTERPRETAÇÃO ENTRE A JURISDIÇÃO DA Corte Interamericana de Direitos Humanos e o Supremo Tribunal Federal quanto a LEI DE ANISTIA 612

Carla Ribeiro Volpini Silva e Bruno Wanderley Junior

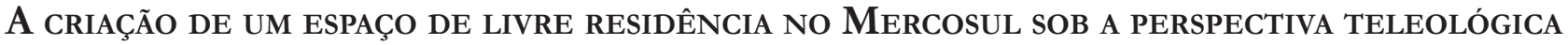
DA INTEGRAÇÃo REGIONAL: ASPECTOS NORMATIVOS E SOCIAIS DOS ACORDOS DE RESIDÊNCIA ....... 631

Aline Beltrame de Moura

A funcionalização como tendênCia evolutiva do Direito Internacional e sua conTRIBUIÇÃO AO REGIME LEGAL DO BANCO DE DADOS DE IDENTIFICAÇÃO DE PERFIL GENÉTICO NO BRASIL

Antonio Henrique Graciano Suxberger

O DIREITO INTERNACIONAL E A PROTEÇÃO DOS DIREITOS DE CRIANÇAS E DE ADOLESCENTES EM CONFLITO COM A LEI EM MOÇAMBIQUE

Bernardo Fernando Sicoche

ObTenÇão de PRovas no EXTERIOR: PARA ALÉM dA LEX FORI E LEX DiLigENTIAE. .685 André De Carvalho Ramos 
A Slight Revenge and a Growing Hope for Mauritius and the Chagossians: The UNClos Arbitral Tribunal's Award of 18 March 2015 on Chagos Marine Protected Area (Mauritius v. United Kingdom)

Géraldine Giraudeau

ANÁLISE DA RESPONSABILIDADE INTERNACIONAL DA UCRÂNIA POR VIOLAÇÃo DOS DIREITOS HUmanos na QUeda do voo da Malaysia Airlines (MH17). .728

Daniela Copetti Cravo

NatureZa JURÍdica do DESENVOLVIMENTO SUSTENTÁVEL No DIREITO INTERNACIONAL ........739 Pedro Ivo Diniz

A INFLUÊNCIA Da SOFT LAW NA FORMaÇão do DiREITo AMBIENTAL .767 Leonardo da Rocha de Souza e Margareth Anne Leister

As COMPLICADAS INTER-RELAÇÕES ENTRE OS SISTEMAS INTERNOS E INTERNACIONAIS DE PROTEÇãO DO DIREITO AO MEIO AMBIENTE SADIO. 785 José Adércio Leite Sampaio e Beatriz Souza Costa 


\title{
Criminalidad transnacional organizada en el ámbito del MERCOSUR: ¿Hacia un Derecho Penal Regional?*
}

\author{
Criminalidade transnacional organizada \\ no âmbito do Mercosur: no caminho de um \\ Direito Penal Regional?
}

\author{
Nicolás Santiago Cordini** \\ Mariano Javier Hoet***
}

\section{Resumen}

La criminalidad organizada no es un fenómeno reducido a la política interna de los Estados; su carácter "transnacional” provoca que las políticas criminales adoptadas aisladamente por los Estados fracasen. Si el fenómeno es regional, la respuesta que debe darse tiene que tener el mismo alcance. El objetivo central del presente trabajo es presentar los lineamientos generales de un Derecho Penal Regional tendiente a la prevención y sanción de los delitos de organización a partir del establecimiento de una Corte Penal Regional contra Crimen Transnacional Organizado. A tal fin, utilizando una metodología cualitativa, hemos comparado la legislación, tanto interna como internacional, de los Estados miembros del Mercosur, teniendo en cuenta los posibles factores facilitadores u obstaculizadores a la adopción de una política de este alcance.

Palabras claves. DELITO-ORGANIZACIÓN-TRANSNACIONALIDAD

Transnational organized crime on the MERCOSUR scale: to a Regional Criminal Law?

** Nicolás Santiago Cordini é Dr. en Derecho, Profesor Adjunto e Investigador. de Derecho Penal y Derecho Penal Internaciona da Universidad Nacional del Litoral - Argentina.

*** Mariano Javier Hoet é Profesor Adjunto de Derecho Penal y de Filosofía Social y Contemporánea. Investigador en el área de Policía y Seguridad da mesma Universidade. Emails: nicocordini@yahoo.com.ar e marianohoet@ rectorado.unl.edu.ar

\section{Abstract}

The organized crime is not a phenomena reduced to the state policies; their "transnational" nature causes that criminal policies isolated adopted by the State at the end fail. If the problem is regional, the answer that must be given has to have the same range. The central aim of the present paper is to present the general guidelines of a Regional Criminal Law in order to prevent and punish the organized crimes following the establishment of a Regional Criminal Court against the transnational organized Crime. With this aim in mind, we use a qualitative methodology in order to compare the legislation, as much national as much International, of the States members of Mercosur, taking into account the possible pros and cons in the adoption of a policy of this range. 
Key words

CRIME-ORGANIZATION-TRANSNATIONAL

\section{INTRRODUCCIÓN:}

\subsection{Marco institucional de la investigación.}

La Universidad Nacional del Litoral organiza su arquitectura institucional en materia de investigación en torno a los CAI+D (Curso de Acción para la Investigación y el Desarrollo). La mencionada política consiste básicamente en agrupar por líneas de investigación a los Proyectos de I+D (PI) en Programas de Actividades Científicas y Tecnológicas (PACT), como un modo de facilitar el logro de objetivos concurrentes de dichos proyectos y de hacer más eficientes la adquisición de equipamiento, bibliografía, etc., de uso compartido. También están previstos los denominados PI especiales que por estar orientados a la producción de conocimiento en áreas caracterizadas por la ausencia de líneas de investigación en la temática, no son agrupados en un PACT.

Dentro de la modalidad referida en último término se encuentra nuestro proyecto de investigación, denominado "Globalización y Derecho penal: el fenómeno de la criminalidad organizada. Situación en la legislación argentina y países del MERCOSUR" el cual fue aprobado mediante resolución del Consejo Superior de la UNL 205/13 y se encuentra actualmente en la fase destinada a la consolidación del equipo de investigación y al establecimiento de precisiones acerca del objeto, las fuentes, el método y las estrategias que orientarán nuestro trabajo.

El proyecto tiene como objetivo final la realización de un estudio comparativo en torno a la normativa vigente en materia de "delitos de organización" entre los países miembros del MERCOSUR y países asociados teniendo en cuenta cómo dicha nueva categoría permea la configuración del injusto generando enormes implicancias en relación con el respecto a los principios y garantías constitucionales.

Actualmente el mencionado proyecto se encuentra en la segunda etapa de desarrollo, ya se ha comparado la legislación en la materia de los Estados objeto de aná- lisis $\mathrm{y}$, consiguientemente, se ha ingresado en una etapa propositiva.

El objetivo del presente trabajo consiste en presentar, en términos generales, las estrategias de construcción normativa que, según nuestra perspectiva de análisis, resultan necesarias para abordar el fenómeno objeto de estudio.

\subsection{Los procesos de globalización y glocaliza- ción en la política criminal.}

Los tiempos que corren se encuentran fuertemente caracterizados por la concurrencia de una serie compleja de fenómenos habitualmente denominados "globalización", los que, dicho en términos sencillos refieren a la transformación de esa constelación histórica caracterizada por el hecho de que el Estado, la sociedad y el mercado son coextensivos dentro las mismas fronteras nacionales ${ }^{1}$. Es decir, la crisis de la idea de una autoridad política dominante, suprema y unificada sobre un territorio claramente demarcado ${ }^{2}$. En suma, la crisis de aquello que Weber caracterizó como una comunidad humana que en el interior de un determinado territorio reclama para sí el monopolio de la coacción física legítima (el Estado) ${ }^{3}$. Como resultado de la globalización, el sistema económico internacional en el que los Estados trazan la línea divisoria entre la economía interna y las relaciones comerciales exteriores, se está metamorfoseando en una economía trasnacional.

La globalización coloca a las funciones administrativo-materiales del Estado en contextos crecientemente volátiles que exceden en mucho la capacidad de cualquier Estado individual para influir en decisiones y resultados. Este proceso de deterioro de las fronteras no afecta únicamente a las economías; impacta también sobre las políticas internas globales, el mantenimiento de la paz y de la violencia organizada, los nuevos medios

1 Habermas, Jürgen, El valle de lágrimas de la globalización, Claves, $\mathrm{N}^{\circ}$ 109, 2001, pp. 4-5.

2 Benhabib, Seyla, (2004). Los derechos de los otros. Extranjeros, residentes y ciudadanos, Barcelona: Gedisa, 2004, p. 15.

3 Con más detalle, Heller define al Estado como una unidad de dominación, independiente en lo exterior e interior, que actúa de modo continuo, con medios de poder propios, claramente delimitada en lo personal y lo territorial, con un solo ejército que es, además, permanente, con una única y competente jerarquía de funcionarios y un orden jurídico unitario, imponiendo a los súbditos un deber de obediencia de carácter general. Heller, Hermann, Teoría del Estado, México: Fondo de Cultura Económica, 1992, pp.142-143. 
y redes de comunicación, los florecientes movimientos migratorios y las formas culturales híbridas.

En los ámbitos que la globalización quiere confiados al mercado, su propuesta político-criminal básica es la inhibición de lo público, entendida como la funcionalización del Estado a los imperativos de las estrategias que esta propone.

Sin embargo, la desregulación no puede ser total, sino que viene acompañada de políticas de contundente intervención punitiva cuando se trata de asegurar la pax publica requerida por ese mercado. La economía globalizada potencia el intervencionismo punitivo frente a sujetos o comportamientos que estima disfuncionales, criminalizando no sólo la disidencia, sino también la marginalidad provocada por el desempleo o por la inmigración. Siguiendo a Silva Sánchez, acordamos que "Criminalidad organizada, criminalidad internacional y criminalidad de los poderosos son, probablemente, las expresiones que mejor definen los rasgos generales de la delincuencia de la globalización"”.

En este marco se viene desarrollando una nueva concepción acerca de lo delictivo, centrada en elementos tradicionalmente no identificados con la delincuencia; en particular, la "organización", expresada a través de la idea de "criminalidad organizada".

Frente a este fenómeno los Estados se encuentran en una situación de dificultad (cuando no de imposibilidad) de desplegar una política criminal adecuada. El hecho de que las organizaciones operen allende las fronteras estatales, ámbito dentro del cual el Estado puede desplegar su facultad de imperio, sumado a la escasez de recursos para desarrollar las mencionadas políticas y a la connivencia que encuentran dichas organizaciones con actores que operan en diversos niveles de intervención en la prevención y sanción del delito (control de fronteras, cuerpo de policía, sistema judicial, sistema penitenciario) redunda, todo ello, en que la política criminal que se adopte se convierta en meramente simbólica.

Ante esta situación la respuesta no puede ser local, la política criminal que se desarrolle al efecto debe abarcar la misma dimensión del fenómeno que se trata de prevenir; si el fenómeno criminológico es regional, la respuesta debe tener dicho alcance. De lo contrario,

4 Silva Sánchez, Jesús-María, (1999). La expansión del Derecho penal. Aspectos de la política criminal de las sociedades postindustriales, Madrid: Civitas, 1999, p. 86. quedaría reducida a un conjunto de declaraciones de buenas intenciones.

El objetivo general de la presente investigación será determinar los lineamientos generales de una política criminal regional tendiente a la prevención y sanción de los delitos de organización a partir del establecimiento de una Corte Penal Regional contra Crimen Transnacional Organizado

\section{Metodología.}

La metodología seleccionada a los efectos de realizar el presente trabajo de investigación se basa en herramientas que se corresponden con una estrategia metodológica cualitativa. Se identifican como unidades informantes las siguientes: (i) Legislación penal de los Estados partes del MERCOSUR, en la que se recepte el elemento "organización"; demás legislación internacional en la materia (Convención de Naciones Unidas contra la Delincuencia Organizada Transnacional y sus Protocolos, Estatuto de Roma de la Corte Penal Internacional, Convención de Naciones Unidas Contra el Tráfico Ilícito de Estupefacientes y Sustancias Psicotrópicas, Convención Americana Sobre Derechos Humanos, Tratados, Protocolos y Acuerdos del MERCOSUR, etc.) y, finalmente, sentencias jurisprudenciales; (ii) Doctrina jurídica: Revistas jurídicas especializadas en la temática penal tanto nacionales como extranjeras (iii) Obras bibliográficas versadas sobre la temática de los delitos de organización y sobre jurisdicción Internacional en materia penal.

Respecto de las técnicas de investigación, recurrimos al análisis clásico de documental: análisis de contenido. Para ello se construirán una serie de instrumentos (fichas de análisis) adecuados para cada tipo de documento. Ello permitirá la sistematización de datos, posibilitando su correlación y su posterior procesamiento, a fin de constituir una muestra representativa sobre: 1) Legislación, 2) Sentencias jurisprudenciales, 3) Doctrina jurídica.

\section{Resultados.}

A continuación analizaremos los resultados alcanzados en función de los objetivos propuestos. 


\subsection{Primer objetivo: determinar el concepto de "organización": ¿De qué se trata la criminalidad organizada?}

Siguiendo a Lampe, sostenemos que al investigar en materia de "crimen organizado", no contamos con un concepto, en tanto objeto de estudio, como punto de inicio ${ }^{5}$. Por el contrario, el verdadero propósito del estudio sobre "crimen organizado" o, para ser más precisos utilizando el léxico jurídico-penal, "delitos de organización", es determinar si tal fenómeno existe o no y, en caso afirmativo, establecer "¿de qué se trata?". Una definición de "delito de organización" es, por lo tanto, un posible resultado antes que una condición previa del estudio de la criminalidad organizada ${ }^{6}$.

La existencia de delitos cometidos a través de organizaciones criminales no es un fenómeno novedoso en el Derecho Penal. Lo que resulta extraño al buen y viejo Derecho Penal liberal es la expansión de la categoría “organización” dentro de las legislaciones penales. Esta reorientación político-criminal se manifiesta a través de diversas variantes. Dichas manifestaciones no surgieron al unísono sino, por el contrario, han ido apareciendo en diversas oleadas y a través diferentes vectores que hoy pueden ser comprendidos bajo el concepto de "expansión del Derecho Penal"”.

5 Lampe, Klaus von, (2009). The study of organised crime: An assessment of the state of affairs. En Karsten Ingvaldsen, Vanja Lundgren Sørli (Eds.), Organised Crime: Norms, markets, regulation and research, Oslo: Unipub, 2009, p. 166.

6 Kelly, R.J., Criminal Underworlds: Looking Down on Society of Bellow. En Kelly R.J. (Ed.) Organized crime: Crosscultural studies. Totowa, NJ: Rowman \& Littlefield, 1986, pp. 10 y ss.

7 La denominada expansión del Derecho Penal, siguiendo a Silva Sánchez, se basa en la creación de nuevos bienes jurídico-penales (v. gr. El medio ambiente, la paz, el tráfico económico), en la ampliación de los espacios de riesgos jurídico-penalmente relevantes (disminución de los espacios de riesgo permitido), en la flexibilización de las reglas de imputación y en la relativización de los principios político-criminales.

Como causas de este fenómeno se mencionan: a) La efectiva aparición de nuevos riesgos producto de la complejización de las interacciones humanas; b) La sensación social de inseguridad que generan las dificultades de adaptación de la población a sociedades en continua aceleración; c) La configuración de una sociedad de sujetos pasivos; d) La identificación de la mayoría social con la víctima del delito, reinterpretando al ius puniendicomo "la espada de la sociedad contra la delincuencia de los poderosos"; e) El descrédito de otras instancias de protección, resignificando al Derecho penal como único instrumento eficaz de pedagogía político social; f) El surgimiento de nuevos gestores de la moral colectiva y del recurso al Derecho penal para la protección de sus respectivos intereses (organizaciones ecologistas, feministas, de consumidores, de vecinos, pacifistas o antidiscriminatorias); g) El desprecio por las formas (garantías), que responde siempre a la supuesta constatación de la
Ellos son: a) la tipificación de delitos que serían característicos de tal forma de criminalidad (p. ej. el delito de trata de personas) ${ }^{8}$; b) la introducción del elemento agravante de organización en una serie de delitos más o menos tradicionales (p. ej. el caso del delito de robo calificado 9 cuando es cometido en banda); y por último, 3) los clásicos delitos de pertenencia a una organización como es el caso del delito de asociación ilícita ${ }^{10}$.

ineficiencia de las mismas. Silva Sánchez, Jesús-María, La expansión del Derecho penal. Aspectos de la política criminal de las sociedades postindustriales, Madrid: Civitas, 1999, pp. 18-60.

Diez Ripollés rechaza la postura de Silva Sánchez considerando que la denominada "expansión del derecho penal" presenta características de dos modelos diferentes, el de la sociedad del riesgo y el de la seguridad ciudadana, que abordan realidades diferentes desde perspectivas ideológicas diversas y que, por tanto, merecen un tratamiento diferenciado. El concepto de expansión deja ya de referirse primordialmente a las nuevas formas de criminalidad propias de la sociedad del riesgo, las cuales pasan a ocupar dentro de ese nuevo concepto de expansión, un lugar marginal, tanto cuantitativa como cualitativamente Diez Ripollés, José Luis, La política criminal en la encrucijada, Buenos Aires: B de F, 2007, p. 132. En consecuencia, la identificación de la mayoría social con la víctima del delito, el descrédito de otras instancias de protección, o bien el surgimiento de nuevos gestores atípicos de la moral colectiva, entre otros, son característicos del modelo de la seguridad ciudadana y no del de la sociedad del riesgo, p. 156.

8 Artículos 142 bis y 142 ter del Código Penal argentino, artículos 231 y 231A Código penal brasileño; artículos 78, 79 y 80 Ley de migraciones 18250 de la República Oriental del Uruguay; artículo 129 del Código penal paraguayo modificado por los artículos 6, 7 y 8 Ley No 2396/04; art 41 Ley Orgánica contra la Delincuencia Organizada y Financiamiento al Terrorismo, que fue publicada en Gaceta Oficial número 39.912 del 30 de abril de 2012 de la República Bolivariana de Venezuela.

9 Así el código penal argentino art. 166 inc. $2^{\circ}$ in fine establece el supuesto en que fuese cometido en despoblado y en banda o en sentido similar el art 165 del Código penal paraguayo establece la modalidad agravada Cuando el autor hurtara (...) como miembro de una banda que se ha formado para la realización continuada de robos y hurtos... Respecto a la norma penal argentina, Boumpadre entiende que "banda" es sinónimo de asociación ilícita. Véase Boumpadre, Jorge, Derecho penal: parte especial, T. II, Corrientes: Mario A. Viera Editor, 2001, p. 74.

10 Así el artículo 210 Código Penal argentino pune al que "tomare parte de una asociación o banda de tres o más personas destinada a cometer delitos por el sólo hecho de ser miembro de la asociación"; el delito de Associação Criminosa del artículo 288 del código penal brasileño que pune cuando "Associarem-se 3 (três) ou mais pessoas, para o fim especifico de cometer crimes"; El código penal de Uruguay en su artículo 150 establece la "Asociación para delinquir" estableciendo que "Los que se asocien para cometer delitos, será castigados por el simple hecho de la asociación..."; el código penal paraguayo contiene en su artículo 239 tipifica la "Asociación criminal" en el que sanciona a "El que: 1. creara una asociación estructurada jerárquicamente u organizada de algún modo, dirigida a la comisión de hechos punibles; 2 fuera miembro de la misma o participara de ella; 3. la sostuviera económicamente o la proveyera de apoyo logístico; 4. prestara servicios a ella; o 5. la promoviera,"; por su parte el código penal venezolano contiene el delito de "agavillamiento" en su artículo 286 que se 
Conforme a las legislaciones de los Estados mercosureños (véase nota al pie n. 5) el injusto sistémico de la organización criminal (el tomar parte de la asociación o asociarse) es un injusto autónomo, independiente de los delitos concretos (delitos fines) que se puedan cometer a través de ella.

El fenómeno de la proliferación de delitos cometidos a través de una "organización" suele caracterizarse por, al menos, dos rasgos:

a) La reducción de la estructura organizativa exigida para apreciar la existencia de una "organización delictiva":

En principio, la organización criminal como sistema de injusto tiene una dimensión institucional - de institución antisocial - que hace de ella no sólo algo más que la suma de sus partes, sino también algo independiente de la suma de las partes. Siguiendo a Silva Sánchez, podemos definir a la organización criminal de la siguiente manera:

"una organización delictiva es un sistema penalmente
antijurídico (strafrechtliches Unrechtssystem), o sea, un
sistema social en el que las relaciones entre los
elementos del sistema (básicamente, personas) se
hallan funcionalmente organizadas para obtener
fines delictivos. La organización criminal como
sistema de injusto tiene una dimensión institucional
- de institución antisocial - que hace de ella no sólo
algo más que la suma de sus partes, sino también
algo independiente"11.

Es en dicha dimensión institucional donde radica su diferencia específica respecto a las meras agrupaciones coyunturales para cometer delitos.

En este sentido se manifiesta el preámbulo de la Convención de Naciones Unidas contra la Delincuencia Organizada Transnacional cuando dice:

\begin{abstract}
"Alineadas contra esas fuerzas constructivas (sociedad civil), cada vez en mayor número y con armas más potentes, se encuentran las fuerzas de lo que denomino la 'sociedad incivil'. Se trata de terroristas, criminales, traficantes de drogas,
\end{abstract}

constituye "Cuando dos o más personas se asocien con el fin de cometer delitos, cada una de ellas será penada, por el solo hecho de la asociación". Además, la Ley Orgánica contra la Delincuencia Organizada y Financiamiento al Terrorismo, que fue publicada en Gaceta Oficial número 39.912 del 30 de abril de 2012 de la República Bolivariana de Venezuela establece en su artículo Artículo 37 que "Quien forme parte de un grupo de delincuencia organizada, será penado o penada por el solo becho de la asociación".

11 Silva Sánchez, Jesús-María, (2008). La 'intervención a través de organización', ¿una forma moderna de participación en el delito? En Cancio Melia, M., et al. Delitos de organización, Buenos Aires: B de F, p. 95 tratantes de personas y otros grupos que desbaratan las buenas obras de la sociedad civil. Sacan ventaja de las fronteras abiertas, de los mercados libres y de los avances tecnológicos que tantos beneficios acarrean a la humanidad. Esos grupos prosperan en los países con instituciones débiles y no tienen escrúpulos en recurrir a la intimidación o a la violencia. Su crueldad es la verdadera antítesis de lo que consideramos civil. Son poderosos y representan intereses arraigados y el peso de una empresa mundial de miles de millones de dólares; pero no son invencibles".

Como vemos, el fundamento de su tipificación penal estaría relacionado a que dichas organizaciones suponen un incremento de la peligrosidad frente a autores individuales o concertados de modo esporádico (participación), es decir, su cualidad de disponer de multiplicación de los distintos factores de riesgo respecto de los bienes jurídicos individuales afectados por las infracciones cometidas a través de la organización.

El crimen organizado se caracteriza por ser un tipo de delincuencia que, por lo general, se presenta bajo la forma de una estructura organizada de poder, de cierta permanencia o continuidad temporal, integrada en un sistema vertical que le posibilita alcanzar cierto nivel de coordinación central en sus actividades. Según Lampe cinco requisitos fundamentales distinguen a la organización criminal de la multiplicidad de partícipes concretados de modo esporádico, ellos son: 1) ingreso de recursos que posibilitan o facilitan la comisión de hechos ilícitos; 2) una ideología de justificación de las conductas criminales; 3) un status social; 4) seguridad ante la persecución penal y 5) seguridad ante otros criminales ${ }^{12}$.

En este sentido se manifiesta la Convención de Naciones Unidas contra la Delincuencia Organizada Transnacional define "Por grupo organizado" a "un grupo estructurado de tres o más personas que exista durante cierto tiempo y que actúe concertadamente con el propósito de cometer uno más delitos graves 13 o delitos tipificados con arreglo a la presente Convención" (art. 2') Por "grupo estructurado", por su parte, la Convención lo define como "un grupo no formado fortuitamente para la comisión inmediata de un delito y en el que no necesariamente se haya asignado a sus miembros funciones formalmente definidas ni haya continuidad en la condición de miembro o exista una estructura desarrollada" (art. 2 c);

12 Lampe, Klaus von, (2013). Was ist ,Organisierte Kriminalität'?, ApuZ, 63. Jahrgang 38-39/2013, p. 6.

13 Art 2 b) Por "delito grave" se entenderá la conducta que constituya un delito punible con una privación de libertad máxima de al menos cuatro años o con una pena más grave; 
Sin embargo, el concepto de "organización" en las legislaciones nacionales tiende a ser un concepto laxo que no distingue entre la criminalidad organizada en sentido estricto (macrocriminalidad o criminalidad de los poderosos) y la mera criminalidad de bandas. El requisito que tiende a hacerse más flexible debido a que las legislaciones analizadas (véase nota al pie n. 5), no exigen la efectiva comisión de delitos sino que es requisito suficiente para punir a sus miembros la existencia de una organización "el tomar parte" de la asociación destinada a cometer delitos. Demás requisitos, por ejemplo, el contar con una de tipo estructura militar, rasgo que ostenta dentro de la organización o la finalidad específica de ésta, constituyen agravantes del delito, pero no son requisitos fundamentales para su existencia.

b) La reducción de la gravedad de los ilicitos que han de constituir el objetivo de tal organización para que ésta sea calificada como "criminal".

Si bien la Convención de Naciones Unidas contra la Delincuencia Organizada Transnacional es aplicable a ilícitos graves que ella misma define como la conducta que constituya un delito punible con una privación de libertad máxima de al menos cuatro años o con una pena más grave (art. 2 b), los ordenamientos jurídicos nacionales contienen legislaciones en la materia aplicables a delitos de criminalidad media o delitos de escasa gravedad. Basta con analizar la figura conocida "asociación ilícita" o "Asociación para delinquir", en la cual no se hace ninguna distinción en torno a la gravedad de los delitos-fines de la organización criminal ${ }^{14}{ }^{15}$.

\subsection{Segundo objetivo: Determinar el ámbito es- pacial de la solución jurídica a adoptar: el Dere- cho Penal Internacional: su status disciplinario}

La idea de un Derecho Penal Internacional como disciplina autónoma todavía sigue siendo resistida espe-

14 Es necesario destacar que la figura básica de "asociación ilícita" en nuestro ordenamiento penal es anterior a la ratificación de la Convención antes señalada por la República Argentina.

15 El hecho de que la figura de "asociación ilícita" sea susceptible de aplicación a organizaciones cuya finalidad delictiva (delitofin) lo constituyan ilícitos de escasa gravedad genera inconsistencias porque si llegase a concurrir el delito de asociación ilícita con un delito de menor gravedad, el delito de asociación ilícita - considerado como acto preparatorio independientemente penado desde la perspectiva del iter criminis - sería más relevante a los efectos penales que el delito fin efectivamente cometido y, por lo tanto, sería el artículo correspondiente a la asociación ilícita el que fijaría las reglas de concursos de delitos por ser el de mayor gravedad. cialmente por la Ciencia del Derecho Penal. Dicha resistencia se basa en que esta rama del derecho representa la máxima expresión del ejercicio soberano del Estado, que este último ejerce con exclusividad. La constitución del Derecho Penal como disciplina científica viene de la mano de formación del Estado moderno, a través de la imposición de límites al príncipe o soberano a la hora de perseguir y castigar los crímenes (ius Puniendi). Dicho en otros términos, el ejercicio de la facultad de castigar, constituye la máxima expresión del ejercicio de la soberanía.

La idea de un Derecho Penal de naturaleza internacional nació como consecuencia de los crímenes de masas cometidos durante el siglo XX. A partir de la persecución y sanción de tales delitos a través de la constitución de tribunales ad hoc y ex post facto16 se fue originando un conjunto de reglas que podríamos denominar "Derecho Penal Internacional". Sin embargo, tales reglas no están exentas de críticas, puesto que violan principios básicos del Derecho penal tales como el de legalidad o la garantía del juez natural ${ }^{17}$. Según Ambos "el carácter esencialmente retroactivo de este tipo de jurisdicción” es "el defecto congénito de los tribunales ad hoc" ${ }^{\prime 18}$. Tornándose en soluciones políticas de los vencedores sobre los vencidos en flagrante violación a las garantías básicas que otorga el Derecho Penal.

Dichas irregularidades han sido salvadas a partir del Estatuto de Roma que crea la Corte Penal Internacional (CPI), siendo el primer instrumento de tutela jurisdiccional internacional de naturaleza permanente, penal e independiente, facultado para investigar, perseguir y sancionar, de manera complementaria a los Estados Miembros, a los presuntos autores de determinados delitos a saber, aquellos que son considerados como los más graves por la Comunidad Internacional en su conjunto: genocidio, crímenes de lesa humanidad, crímenes de guerra y crimen de agresión.

16 El Tribunal Militar Internacional de Núremberg (1945); el Tribunal Militar Internacional de Tokio (1946); el Tribunal Penal Internacional para la ex-Yugoslavia, con sede en la Haya (1993), el Tribunal Militar Internacional para los crímenes cometidos en Ruanda (1994), en Arusha y el Tribunal para el Genocidio Camboyano (2006)

17 Un ejemplo claro de violación fue el Tribunal Militar Internacional de Núremberg que no garantizó (prohibiéndolo expresamente) el derecho de recusación que goza todo sujeto sometido a proceso. 18 Véase, Ambos, Kai, El derecho penal internacional en la encrucijada: de la imposición ad hoc a un sistema universal basado en un tratado internacional. Política Criminal, (vol. 5, núm. 9, 2010, págs. $237-256$ 
A partir de la conformación de la CPI podemos hablar de un "Derecho Penal Internacional" basado en los principios de legalidad, personalidad de la pena, ne bis in idem, jurisdicción complementaria, entre otros.

Esta nueva disciplina, que combina potestad punitiva con la dimensión internacional, parte de la premisa de un Derecho penal no basado en la idea de soberanía estatal, es decir un Derecho penal que ejerza el ius puniendi sin soberano. Dicha solución se hace posible a partir del desarrollo de un concepto de ciudadanía global, en nuestro caso regional, basado en la protección de los derechos humanos fundamentales garantizados por múltiples Tratados, tanto de escala universal como regional. No debemos de olvidar, sin embargo, que esta disciplina aún se encuentra en una estadio fluido y en formación.

\subsection{Tercer objetivo: determinar posibles facto- res facilitadores u obstaculizadores para la insti- tucionalización de un Derecho Penal Regional:}

A la hora de discutir la formación de un Derecho Penal de Escala Regional debemos tener en cuenta aquellos factores que sostienen nuestra línea de pensamiento y también aquellos que pudiesen constituir un obstáculo a dicha posibilidad. A continuación abordaremos los factores a favor y en contra que posee el diseño de una política de este calibre.

\section{a) Factores a favor}

\section{a.1) La Corte Penal Internacional.}

La CPI ha constituido el primer hito en la constitución de una jurisdicción permanente tendiente a juzgar y sancionar los delitos, considerados más graves por la Comunidad Internacional, cometidos por particulares. Todos los Estados objeto de Estudio han suscripto el Estatuto de Roma ${ }^{19}$ y, en consecuencia, han cedido jurisdicción en esta materia. Bien es verdad que aquí no juega el argumento a fortiori y, de hecho, los Estados parte de MERCOSUR podrían no estar interesados en ceder jurisdicción en materia de delitos menos gravosos. Sin embargo, del éxito de la CPI y de otros Tratados

19 Los Estados partes de MERCOSUR han suscripto el mencionado tratado en las siguientes fechas: Argentina: 08/02/2001; Brasil: 20/06/2002; Paraguay: 14/05/2001; Uruguay: 28/06/2002, Venezuela: 07/06/2000.
Internacionales a los que los Estados objeto de estudio han ratificado, constituyen un argumento potente para evitar el rechazo a una jurisdicción regional en materia de delitos de organización.

a.2) MERCOSUR y sus múltiples acuerdos.

Dentro de la estructura del MERCOSUR existen múltiples acuerdos celebrados entre los Estados partes y otros Estados asociados, cuyo objetivo es la cooperación internacional en materia penal. A modo de ejemplo, citamos:

_Acuerdo de Asistencia Jurídica Mutua en Asuntos Penales entre los Estados Partes del MERCOSUR, la República de Bolivia y la República de Chile (Buenos Aires, 18 de Febrero de 2002)

_Acuerdo contra el Tráfico Ilícito de Migrantes entre los Estados Partes del MERCOSUR (Belo Horizonte, 16 de diciembre de 2004).

_Acuerdo contra el Tráfico Ilícito de Migrantes entre los Estados Partes del MERCOSUR, la República de Bolivia y la República de Chile (Belo Horizonte, 16 de diciembre de 2004).

a.3) Convención de las Naciones Unidas contra la Delincuencia Organizada Transnacional y sus Protocolos.

Adoptada por la Res. 55/25 de la Asamblea General de Naciones Unidas del año 2000, la presente Convención establece el marco general de lo que debe entenderse por delincuencia organizada transnacional, a la vez que prevé medidas, tendientes a adoptar por los Estados partes, tendientes a prevenir, reprimir y sancionar los delitos definidos por la Convención y sus Protocolos.

Si bien no es objetivo de esta Convención establecer una jurisdicción internacional en la materia; esta normativa, no obstante, establece múltiples medidas de cooperación judicial, que sirven de sustento a una posible Corte Regional en la materia.

a.5) Sistemas penales similares.

Otra argumento a favor de la constitución de un Derecho Penal Regional en materia de delincuencia Transnacional Organizada, es el hecho que los Estados partes de Mercosur comparten en materia penal (tanto en lo que respecta al Derecho sustantivo como al Derecho Procesal) sistemas similares. Todos los países siguen la tradición jurídica continental europea y, en la dogmática jurídico-penal, la denominada teoría del delito Podemos 
caracterizar a la teoría del delito como un mecanismo de imputación, es decir, como un "medio técnico-jurídico para establecer a quien se debe imputar ciertos hechos y quien debe responder por ellos personalmente" ${ }^{20}$. Ahora bien, la teoría del delito no es el único mecanismo de imputación de aplicabilidad posible, por el contrario, en muchos países -por ejemplo Estados Unidos, Gran Bretaña, Francia, en alguna medida Italia, etc.- se utilizan herramientas dogmáticamente menos elaboradas, lo cual es una consecuencia de procesos históricos diferenciados con, por ejemplo, Alemania y España, países en los cuales los códigos penales aparecieron tardíamente, es decir, cuando la ciencia del derecho penal -dogmática- había alcanzado ya un grado de evolución más que considerable trabajando en la construcción de sistemas conceptuales que desbordaban los textos positivos.

El hecho que todos los Estados objeto de estudio compartan el mismo sistema de imputación constituye un factor trascendente para la consolidación de un Derecho Penal Regional. Asimismo, analizado los diversos modelos de teoría del delito, existe una gran similitud en las teorías penales propuestas por Raúl Eugenio Zaffaroni en Argentina, Juares Estevam Xavier Tabares en Brasil, Gonzalo Fernández en Uruguay ${ }^{21}$, etc., reforzando el argumento antes planteado.

A la vez, en materia Procesal Penal se observa que los diversos Estados que conforman Mercosur se encuentran en una tendencia hacia la consolidación del denominado sistema acusatorio.

La similitud de los sistemas penales constituye una gran ventaja que presenta nuestro bloque regional frente a otros, por ejemplo la Unión Europea, en los cuales paso previo a acuerdos en materia penal, deben establecer principios comunes mínimos entre los múltiples sistemas penales, lo que genera reticencias por parte de los Estados tener flexibilizar determinados postulados básicos de sus respectivos sistemas.

20 Bacigalupo, Enrique, Derecho Penal. Parte general, $2^{a}$ edición, Buenos Aires: Hammurabi, 1999, p. 197. La teoría analiza el hecho delictivo como un sistema de filtros a partir de las categorías de: acción, tipo, antijuridicidad y culpabilidad. Veáse, Murmann, Uwe, Grundkurs Strafrecht. Allgemeiner Teil, Tötungsdelikte, Körperverletzungsdelikte, $2^{\mathrm{a}}$ edición, München: C.H. Beck., 2013, pp. 50 yss.

21 Véase, ZaffaronI, Raúl, Alagia, A., et al., Derecho penal: Parte General, $2^{a}$ edición, Buenos Aires: Ediar, 2003; Tavares, Juarez Estebam Xavier, Teoría del Injusto penal, Buenos Aires: B de F, 2010; Fernández, Gonzalo, Bien jurídico y sistema del delito, Buenos Aires: B de F, 2004.

\section{b) Factores en contra.}

b.1) La cesión de soberanía.

El Derecho penal es un producto político de los Estados nacionales nacidos en el siglo XIX. Desde la perspectiva del derecho interno, aparece como el último bastión de la soberanía nacional y, en la actualidad, se afronta a un problema transnacional conocido como "criminalidad transnacional" lo que implica que los hechos ilícitos no reconocen las fronteras estatales. Ante este panorama los Estados guiados por la finalidad de evitar todo tipo de paraísos jurídicos-penales suscriben Convenciones Internacionales para rearmarse frente a modelos de delincuencia que crean una fuerte sensación de inseguridad no sólo a los ciudadanos, sino también a los mismos Estados.

Bien señala Kristen Hessler, asumir que la soberanía estatal deba incluir incluso un justificable derecho por parte de los Estados para bloquear tribunales penales internacionales está tensión con la dimensión moral de la soberanía y el proyecto de una justicia global, en la medida que se corre el riesgo de que se adopten medidas a favor del estado moralmente inaceptables tanto en la teoría como en la práctica ${ }^{22}$.

b.2) Diferencias conceptuales en la legislación de determinados delitos.

Si bien los Estados objeto de análisis comparten sistemas penales similares, difieren, no obstante, en el tratamiento específico de los delitos objeto de análisis. Así en la actualidad, determinada actividad, puede ser considerada delictiva en un Estado, y ser lícita en otro. Puesto que toda norma penal debe ser interpretada restrictivamente, excluyéndose toda extensión analógica de la misma. En la práctica, si comparamos las diversas descripciones que efectúan las distintas legislaciones, puede darse el caso, no tan infrecuente, que una determinada conducta esté prohíba conforme a la legislación de un Estado y, sin embargo, sea lícita en otro.

El objetivo de dar una respuesta uniforme a esta problemática a través de un Tratado no es fácil. A la hora de negociar una Convención, los Estados firmantes no renuncian a sus pretensiones punitivas, por lo que

22 HESSLER, Kristen, "State Sovereignty and International Juridiction" en May, Larry, Hoskins, Zachary (Eds.), International Criminal Law and Philosophy, New York: Cambridge University Press, 2000, p. 57 
el resultado de dicho acuerdo será más bien la sumatoria de dichas pretensiones que una armonización de la legislación en la materia.

Un proceso de internacionalización del Derecho Penal tal como lo planteamos, va necesariamente unido a una armonización de las legislaciones de los Estados parte. Quizás este sea el mayor desafío en aras de lograr el objetivo general.

\section{Conclusiones.}

Las conclusiones a las que hemos arribado conforman un boceto en el cual se receptan las líneas generales que consideramos que debe tener la política criminal regional tendiente al establecimiento de una "Corte Penal Regional contra el Crimen Transnacional Organizado"

\subsection{Teoría del delito como instrumento de aná- lisis:}

Las reglas de imputación, o sea, de atribución de responsabilidad, así como sus causales de exclusión (casos de error, causales de justificación, causas de exclusión de la culpabilidad, etc.) deberán estar en concordancia con los postulados de la teoría del delito. Estamos de acuerdo con Ambos, en que dicha teoría debe estar basada en un modelo político-criminal funcional ${ }^{23}$ de derecho comparado consistente en su orientación a los derechos humanos frente a un puro funcionalismo de impronta jakobsiana ${ }^{24}$.

\subsection{Sistema procesal de carácter acusatorio.}

En el que estén representadas la función judicial (el tribunal), la acusación o Fiscalía y el órgano de la Defensa. El proceso deberá ser justo, expedito y se sustanciará con ple-

23 En especial, el modelo propuesto por Claus Roxin que a las categorías básicas de la teoría del Delito, le suma las funciones de la política criminal. Véase, Roxin, Claus, Kriminalpolitik und Strafrechtssystem, $2^{a}$ edición, Berlin-New York: Walter de Gruyter, 1973; Roxin, Claus, Strafrecht: Allgemeiner Teil. Band I. Grundlagen der Aufbau der Verbrechenslehre", $4^{a}$ edición, München: C. H. Beck, 2006.

24 Ambos, Kai, La construcción de una parte general del derecho penal internacional. En Temas actuales del derecho penal internacional. Contribuciones de América Latina, Alemania y España, Jan Woischnik (Ed.), Montevideo: Konrad-Adenauer-Stiftung Verlag, 2005, p. 22. no respeto de los derechos del sujeto sometido a proceso y teniendo debidamente en cuenta la protección de los demás sujetos involucrados en el mismo, a saber, de las víctimas ${ }^{25}$ y de los testigos. Son de especial importancia en este punto las "100 Reglas de Brasilia sobre el Acceso a la Justicia de las Personas en Condición de Vulnerabilidad” adoptada por la XIV Cumbre Judicial Iberoamericana que establece reglas, entre otras, tendientes a "mitigar los efectos negativos del delito (victimización primaria) Asimismo procurarán que el daño sufrido por la víctima del delito no se vea incrementado como consecuencia de su contacto con el sistema de justicia (victimización secundaria)" (art. 5.11)

También se tendrá en cuenta los principios penales establecidos en la Convención Americana sobre Derechos Humanos las sentencias de la Corte Interamericana de Derechos Humanos en las que se ha fijado límites temporales al proceso y a las medidas cautelares (en especial, la prisión preventiva), y en los que se asegura la garantía de la defensa en juicio, la facultad amplia de apelar por parte del sujeto sometido a proceso y/o condenado, etc.

\subsection{Respeto a los principios orientadores del Derecho Penal.}

Legalidad: (nullum crimen sine lege) en función de este principio, nadie será penalmente responsable de conformidad con la Convención que lo establezca, a menos que la conducta de que se trate constituya, al momento de su realización, en un delito de la competencia de la Corte. Por lo que nadie podrá ser considerado culpable por la Corte por una conducta anterior a su entrada en vigor (irretroactividad ratione personae).

Como derivación de este principio, quien sea declarado culpable por la Corte únicamente podrá ser penado de conformidad con el Estatuto que establezca los delitos y las penas correspondientes (nulla poena sine lege).

La definición del delito siempre será interpretada

25 Siguiendo las pautas de las 100 Reglas de Brasilia: “(56) Se promoverá que las víctimas reciban información sobre los siguientes elementos del proceso jurisdiccional:

- Posibilidades de obtener la reparación del daño sufrido

- Lugar y modo en que pueden presentar una denuncia o escrito en el que ejercite una acción

- Curso dado a su denuncia o escrito

- Fases relevantes del desarrollo del proceso

- Resoluciones que dicte el órgano judicial

(57) Cuando exista riesgo para los bienes jurídicos de la víctima, se procurará informarle de todas las decisiones judiciales que puedan afectar a su seguridady, en todo caso, de aquéllas que se refieran a la puesta en libertad de la persona inculpada o condenada, especialmente en los supuestos de violencia intrafamiliar". 
restrictivamente y no se hará extensiva por analogía (probibición de interpretación analógica). En caso de ambigüedad será la norma en cuestión será interpretada en favor de la persona sometida a proceso.

Lesividad: La Corte solo puede intervenir penalmente para amenazar lesiones o puestas en peligro de bienes jurídicos, y no está facultada para castigar las acciones privadas de los hombres que de ningún modo ofendan al orden y a la moral pública, ni perjudiquen a un tercero.

Responsabilidad penal individual: la Corte tendrá competencia respecto de las personas naturales. Esto significa que solo se puede responder penalmente por los hechos en los que se ha intervenido personalmente, sea como autor, cómplice, instigador o auxiliador sub sequens. Esta garantía puede esbozarse negativamente como principio de personalidad de la pena, es decir, si solo se responde por los hechos en los que se ha participado (participación en sentido genérico) la pena no podría extenderse a quienes no han intervenido en el hecho.

Principio de culpabilidad: de él se desprenden dos consecuencias: en primer lugar, que solo se podrá castigar a un sujeto por un hecho culpable, y en segundo, que la gravedad de la pena ha de ser proporcional al grado de culpabilidad. La proporcionalidad de la pena debe darse también con respecto a la gravedad del hecho antijurídico (desvalor de acción y de resultado). A esto último se lo conoce como principio de proporcionalidad del castigo.

Estado de inocencia: fue formulado originariamente como presunción (así el art. 8 inc. 2 de la Convención Americana sobre los Derechos Humanos). Su reformulación conceptual se motivó en las observaciones de que el progreso del proceso se funda en una presunción de culpabilidad (sospecha) y no de inocencia. La mencionada reformulación se operó a partir de la distinción entre las valoraciones (presunción de culpabilidad) de los sujetos facultados para determinar el avance del proceso (y el correlativo incremento de la incriminación) y la situación en la que toda persona se encuentra, conforme a la cual, hasta el dictado por el órgano jurisdiccional competente de un pronunciamiento firme de responsabilidad penal toda persona es inocente. En lo que respecta a la proyección del principio dentro del proceso penal, entre otros aspectos importantes, nos permite explicar el alcance meramente procesal de las medidas de coerción que pueden limitar o restringir la libertad del imputado (como por ejemplo, la prisión preventiva).
Estas medidas únicamente serán legítimas cuando se orienten a evitar que el imputado rehúya la acción penal o entorpezca el desarrollo del proceso. Cualquier otra finalidad para las mismas queda excluida.

Ne bis in idem: nadie será procesado por la Corte en razón de conductas calificadas como delito por éstas por los cuales ya hubiese sido condenado o absuelto por la Corte o por un juez o tribunal estatal. La Corte, sin embargo, podrá procesar a una persona solo si el anterior proceso sustanciado en otro tribunal tuviese como propósito sustraer al acusado de su responsabilidad por crímenes de la competencia de esta Corte; o no hubiese sido instruido en forma independiente o imparcial de conformidad con las debidas garantías procesales reconocidas por el derecho internacional o lo hubiere sido de alguna manera que, en las circunstancias del caso, fuere imposible someter a la persona a la acción de la justicia.

\subsection{Competencia Material.}

La Corte tendrá competencia material para investigar y enjuiciar a los presuntos responsables, sin importar el cargo, de haber cometido manera organizada los crímenes de carácter transnacional. El ejercicio de su jurisdicción tendrá carácter complementario respecto de las jurisdicciones nacionales.

\subsubsection{Delitos comprendidos.}

Consideramos que los delitos objeto que serán objeto de persecución y sanción por la Corte serán los abordados Convención de las Naciones Unidas contra la Delincuencia Organizada Transnacional y sus Protocolos, a saber:

(i) Delito de lavado de activos.

(ii) Trata de personas

(iii) Tráfico ilícito de migrantes

(iv) Fabricación y tráfico ilícito de armas de fuego, sus piezas y componentes y municiones.

Además, pese a no ser un delito objeto del Protocolo de Palermo, consideramos necesario incluir el

(v) Tráfico de estupefacientes y sustancias psicotrópicas objeto de la Convención de Naciones 
Unidas que lleva el mismo nombre del año 1988.

Puesto que el tratado constitutivo de la Corte deberá establecer qué delitos van a ser objeto de su competencia, definiéndolos y estableciendo las penas correspondientes, en cumplimiento del principio de legalidad que rige en esta materia. Ante esta situación, los Estados deberán armonizar sus legislaciones en dicha materia a fin de evitar posibles distorsiones. Armonizar las legislaciones permitirá evitar estas lagunas de punibilidad ${ }^{26}$.

\subsection{Competencia personal:}

La Corte ejercerá su competencia sobre los delitos antes señalados que sean cometidos por personas físicas. La competencia se limitará a sólo aquellos que promuevan, dirijan u organicen la asociación. El ejercicio de la acción penal respecto de aquel que tal solo toma parte de la organización criminal o solamente cumple funciones secundarias o auxiliares es exclusiva de los Estados que tengan jurisdicción sobre el hecho. Ampliar la competencia de la Corte a todo aquel que intervenga en una organización criminal implica correr de foco el objetivo de esta institución, que no es otro que combatir la macrocriminalidad.

En debido respeto de Pactos Internacionales en la materia, la Corte no será competente respecto de los autores o partícipes que fuesen menores de 18 años en el momento de la presunta comisión del crimen.

\subsection{Competencia temporal.}

La Corte tendrá competencia únicamente respecto de crímenes cometidos después de la entrada en vigor del Estatuto que le otorgue existencia. Si un Estado se hace parte de dicho Estatuto luego de su entrada en

26 No resulta redundante aclarar que la Corte ejercerá su jurisdicción sólo cuando el delito tenga los componentes de la "organización” y "transnacionalidad". El primero ya lo hemos desarrollado en los resultados. En lo referente a la transnacionalidad seguimos la definición aportada por la Convención de las Naciones Unidas contra la Delincuencia Organizada Transnacional: "El delito será de carácter transnacional si: a) Se comete en más de un Estado; b) Se comete dentro de un solo Estado, pero una parte sustancial de su preparación, planificación, dirección o control se realiza en otro Estado; c) Se comete dentro de un solo Estado, pero entraña la participación de un grupo delictivo organizado que realiza actividades delictivas en más de un Estado; o d) Se comete en un solo Estado, pero tiene efectos sustanciales en otro Estado" (art. 3.2). vigor, la Corté sólo podrá ejercer su competencia respecto a los crímenes cometidos luego de la entrada en vigor del Estatuto respecto de ese Estado.

\subsection{Jurisdicción complementaria.}

Ante la comisión de un delito objeto de persecución por parte de la Corte, el asunto será investigado o enjuiciado por un Estado que tenga jurisdicción sobre él, salvo que no esté dispuesto a llevar a cabo las investigaciones o el juicio o no pueda realmente hacerlo.

La Corte no podrá intervenir si el asunto ya ha sido objeto de investigación por un Estado que tenga jurisdicción sobre él y éste haya decidido iniciar la acción penal contra la persona de que se trate, salvo que la decisión haya obedecido a que no esté dispuesto a llevar a cabo el juicio o no esté en condiciones de hacerlo.

\section{Referencias}

Ambos, Kai (2010). El derecho penal internacional en la encrucijada: de la imposición ad hoc a un sistema universal basado en un tratado internacional. Política Criminal, (vol. 5, núm. 9, 2010, págs. 237-256).

Ambos, Kai, (2005). La construcción de una parte general del derecho penal internacional. En Temas actuales del derecho penal internacional. Contribuciones de América Latina, Alemania y España, Jan Woischnik (Ed.), (pp. 13-40), Montevideo: Konrad-AdenauerStiftung Verlag.

Bacigalupo, Enrique (1999) Derecho Penal. Parte general, $2^{a}$ edición, Buenos Aires: Hammurabi.

Benhabib, Seyla, (2004). Los derechos de los otros. Extranjeros, residentes y ciudadanos, Barcelona: Gedisa.

Boumpadre, Jorge, (2001). Derecho penal: parte especial, T. II, Corrientes: Mario A. Viera Editor.

Cancio Melia, Manuel, Silva Sánchez, Jesús-María, (2008). Delitos de organización, Buenos Aires: B de F.

Diez Ripollés, José Luis, (2007). La política criminal en la encrucijada, Buenos Aires: B de F.

Habermas, Jürgen, (2001). El valle de lágrimas de la globalización, Claves, $\mathrm{N}^{\circ} 109$, pp. 4-10.

Fernández, Gonzalo, (2004). Bien jurídico y sistema del 
delito, Buenos Aires: B de F.

Heller, Hermann, (1992). Teoría del Estado, México: Fondo de Cultura Económica.

HESSLER, Kristen, (2000), "State Sovereignty and International Juridiction" en May, Larry, Hoskins, Zachary (Eds.), International Criminal Law and Philosophy. (pp. 39-57), New York: Cambridge University Press,

Kelly, R.J. (1986) Criminal Underworlds: Looking Down on Society of Bellow. En Kelly R.J. (Ed.) Organized crime: Crosscultural studies. (pp. 10-31) Totowa, NJ: Rowman \& Littlefield.

Lampe, Klaus von, (2013). Was ist, Organisierte Kriminalität?, ApuZ, 63. Jahrgang 38-39/2013, pp. 3-8

Lampe, Klaus von, (2009). The study of organised crime: An assessment of the state of affairs. En Karsten Ingvaldsen, Vanja Lundgren Sørli (Eds.), Organised Crime: Norms, markets, regulation and research, (pp. 165-211) Oslo: Unipub.

Murmann, Uwe, (2013). Grundkurs Strafrecht. Allge- meiner Teil, Tötungsdelikte, Körperverletzungsdelikte, $2^{\mathrm{a}}$ edición, München: C.H. Beck.

Roxin, Claus, (1973), Kriminalpolitik und Strafrechtssystem, $2^{a}$ edición, Berlin-New York: Walter de Gruyter.

Roxin, Claus, (2006). Strafrecht: Allgemeiner Teil. Band I. Grundlagen der Aufbau der Verbrechenslehre“, $4^{a}$ edición, München: C. H. Beck.

Silva Sánchez, Jesús-María, (2008). La 'intervención a través de organización', ¿una forma moderna de participación en el delito? En Cancio Melia, M., et al. Delitos de organización, (pp. 87-188). Buenos Aires: B de F.

Silva Sánchez, Jesús-María, (1999). La expansión del Derecho penal. Aspectos de la política criminal de las sociedades postindustriales, Madrid: Civitas.

Tavares, Juarez Estebam Xavier, (2010). Teoría del Injusto penal, Buenos Aires: B de F.

ZaffaronI, Raúl, Alagia, A., et al., (2003). Derecho penal: Parte General, $2^{\mathrm{a}}$ edición, Buenos Aires: Ediar. 
Para publicar na Revista de Direito Internacional, acesse o endereço eletrônico www.rdi.uniceub.br ou www.brazilianjournal.org.

Observe as normas de publicação, para facilitar e agilizar o trabalho de edição. 